Psychiatry. Other active Groups are those for Dependence and Addiction and Biological Psychiatry. All these appear to be thriving in a very healthy manner.

During these years the College has taken an active interest in the matter of human rights, particularly with regard to the abuse of psychiatry for political purposes (see Sidney Levine's article in the Bulletin, May 1981, p 94). The College passed a number of resolutions condemning this abuse, particularly in the USSR. During my Presidency, I was able to enlist the agreement of the General Council of the Bar to take part in an investigatory commission jointly with the College to visit the USSR and investigate allegations of psychiatric abuse, but permission was not received from the USSR for the visit to take place. The College proposed a resolution for the General Assembly of the World Psychiatric Association meeting in Hawaii, which after amendment by the Australian and New Zealand College of Psychiatrists, was passed by the Assembly. The World Psychiatric Association set up two committees, one to deal with ethical matters in psychiatry, and the College set up its own special committee to consider matters relating to the political abuse of psychiatry, under the Chairmanship of $\mathrm{Dr}$ Peter Sainsbury. This committee has considered allegations of the abuse of psychiatry in other countries, including Argentina. Chile and South Africa.

The Research Committee is not only always ready to help individual research workers in the planning and methodology of their research, but has also launched the College's first research project, an inquiry into ECT.

Other standing committees have also gone from strength to strength. The Programmes and Meetings Committee arranges excellent meetings throughout the year, the Education Committee, in its manifold activities, plays a vital part in the College's affairs, the Collegiate Trainees Committee is actively engaged and is particularly concerned with manpower and the Membership Examination and with training throughout the United Kingdom and Republic of Ireland.

A key person during the period preceding the inception of the College and throughout the past decade has been Miss Natalie Cobbing who, as Secretary of the College, exercises a co-ordinating role without which the College could not function effectively. We are indebted to her and her colleagues, and to $\mathrm{Mr}$ and Mrs Brooks, for all the work they have so faithfully given the College.

This has really been a very brief summary of some of the important activities of the College, and inevitably I have been unable to mention all its achievements and all those who have contributed to its success during the past decade. The College continues to evolve and has already gained in status and recognition throughout the world, for which we can all be justly proud.

\title{
Professor Sir Desmond Pond (1978-1981)
}

Sir Martin Roth and Professor Linford Rees have well documented the achievements of the past ten years, to which I can add but little except to say how proud I am to have been able to join in with these activities and try to continue their far-sighted policies. Nevertheless, there is much that remains to be done, not so much because of what we have failed to do as because of the constantly changing situation in which we work.

As an example, I should like first to mention recruitment and manpower. Though $I$ raised this as a major issue when $I$ became President, little progress has been made. However, the general lines of future policy are now clearer, and the will to implement change will undoubtedly be increased by the recommendations of the House of Commons Select Committee under Renee Short, whose report has just been published. The main difficulty is that, though manpower problems are different in different specialties, we have, nevertheless, to keep roughly in step with the career structure of the medical profession as a whole. Our recruitment from British graduates may improve as a result of the 'popular' specialties of general medicine and surgery making greater efforts to bring home to graduates the advantages of going into the 'shortage' specialties, though it is difficult to know quite what determines popularity and unpopularity among us and whether efforts should be made to change students' views more at the undergraduate than the postgraduate level. We are probably further on than most specialties in providing better arrangements for part-time trainees and parttime consultant appointments, though there is still a long way to go. More difficult is the question of the ratio of trainees to consultants, though there is now movement here, at least at the levels of DHSS and Joint Consultants Committee policy planning. More consultants has always been our policy, but it carries with it the inevitable consequence that some hospitals will be without trainees. What sort of non-trainee, non-consultant doctors may share the workload with the consultant staff is so far an unsolved issue, but I think we are nearer than most specialties to having and accepting a role for career-grade part-time (and probably whole-time) specialists. However, I do not think we have adequately considered the advantages of using general practitioners more, nor the possibilities of the non-medical professionals, like community psychiatric nurses, counsellors, clinical psychologists, etc.

This last consideration brings me to the second matter on which further action is increasingly necessary. This is to remedy the lack of a proper body to represent the interests of the numerous workers in the psychosocial caring field. There are many ad hoc committees and standing committees, but no on-going body which can speak with authority. There are 
at least three areas in which we have many common interests with numerous other professional groups; the first, the whole matter of training in psychotherapy and counselling. Trainees differ greatly in the intensity of their training, the breadth of their experience and their background of academic knowledge, and the various levels do not correspond easily to usual professional boundaries. I believe that there is enough in common between all of the methods of treatment for a greater effort to be made to integrate training schemes. Secondly, there ought to be certain common standards of professional behaviour. A start has been made in this direction in the long on-going Committee on Confidentiality. In spite of tremendous efforts by Professor Linford Rees and Dr Brian Ward, the Chairman and Secretary, respectively, of this inter-disciplinary group, agreement is proving difficult to reach, though much valuable discussion has taken place and it is hoped that a report will soon be published. The Zangwill Committee Report on a Code of Behaviour for Behaviour Therapy is another example of trying to apply standards of professional behaviour across disciplines. The Registration of Psychotherapists is a third topic where standards and training matters overlap. Finally, many of these organizations, including ourselves, have common interests in the prevention of mental disorder and in treatment in the community. The community-based work inevitably implies going beyond the treatment of the individual patient which is the traditional role of the doctor. It implies going beyond even the treatment of the family which is now well-established in psychiatry. I am not sure how many of us are ready to be involved even indirectly in changing the attitudes and behaviour of social groups, including some sort of social action. The problems here will probably be the most intractable, as social and political actions are hard to separate and political action is something that many professional people fight shy of.

As many of you know, before I became President of this College I was Chairman of the Association of Child Psychology and Psychiatry. This is a flourishing multidisciplinary body whose membership is rightly increasing all the time. I hope that all child psychiatrists feel that they should belong to it. Amongst other things, it publishes a first class Journal with an international reputation. But it has little influence in the corridors of power. I have often wondered why it is less influential than many of the bodies to which most of its members belong. Probably it is because ACPP does not control entry into any profession, nor training schemes, nor certificates of competence. These functions which the existing organization that do these things, such as the medical Royal Colleges, guard very jealously, and I suspect that they would be very reluctant to give them up or even accept the need for rationalization across disciplines.

Although many people express satisfaction at the flourishing state of the numerous Sections and Groups that the College has and of the numerous meetings held (even including committees!), I must express some concern at this proliferation-we might do better if we met less often for longer. The central core of general psychiatry needs to be jealously maintained as it is of primary importance for us all. Medicine and surgery, of course, have similar fissiparous tendencies, but I am sure the Royal College of Physicians and the Royal College of Surgeons are right to insist on the MRCP and the FRCS, repectively, as general examinations without which specialization and further training cannot be undertaken. What I say in this connection could be seen to be in conflict with what I have said in the previous paragraph about the need for multidisciplinary training and standards, but I think the contradiction is probably healthy, and I hope it will continue to stimulate discussion and debate.

We are particularly fortunate in having very good relations with the doctors in the DHSS concerned with mental health in all its aspects. Not all the other Royal Colleges have such close contacts. It has enabled us to have informal discussions about many sensitive medico-political issues before they reach the level of formal negotiation. Perhaps Sir Henry Yellowlees' distinguished psychiatric forebears have had a benign ghostly influence! As I write we are awaiting the news of a possible new Mental Health Act, and this will undoubtedly be a major issue for our new President-we could not be in safer and stronger hands to steer us through this and the many other problems that will doubtless emerge in the next few years.

\section{Annual Subscription}

It was with great reluctance that subscription rates for United Kingdom members were increased at the Annual General Meeting in July 1981. Details appear in the Minutes of the Annual Meeting on page 232. You are reminded that your subscription falls due on 1 January, 1982, and that if you do not pay by direct debit or banker's order payment should now be sent to me at the College.

Members whose subscriptions are outstanding for the current year were informed at the beginning of September that unless payment was received by the end of October, they would cease to receive the British Journal of Psychiatry on 1 January, 1982. There are still some subscriptions outstanding, and in their own interest members are requested to make prompt payment of their dues.

The response from members who signed mandates to enable subscriptions to be paid by direct debit has exceeded our early expectations. However, it is hoped that members who have not already agreed to this method of payment will soon do so. Thus continuity of payment is assured even though the subscription varies and no further action is required by the member. Notification of the amount due will be sent annually.
C. M. B. PARE Honorary Treasurer 